\section{Fórum \\ Artigos científicos e a produção em Saúde Coletiva no Brasil. Posfácio}

\author{
Forum \\ Scientific articles and scientific production in \\ Public Health. Postscript
}

Hillegonda Maria Dutilh Novaes 1

Os estudos que tomam a publicação científica como seu objeto ainda são poucos na Saúde Coletiva, e a publicação destes artigos como um Fórum dedicado a esta temática potencializa a sua importância, ao permitir um olhar mais abrangente sobre uma questão que interessa a todos. A definição do recorte temático dos artigos e dos autores contribuiu para aproximar a discussão presente na literatura internacional da "sociologia das ciências", discutida em um dos artigos, do cenário da saúde coletiva brasileira, com a apresentação de análises comparativas elaboradas por seus editores das características dos artigos publicados em duas importantes revistas da área. Essa iniciativa dá continuidade a outras caracterizando esse tema como linha de investigação e de atuação na Saúde Coletiva, como se verifica nos estudos recentes apresentados em reuniões específicas e publicações especiais 1 .

No artigo Produção e Citação em Saúde Coletiva: Um Olhar a Partir dos Periódicos Cadernos de Saúde Pública e Revista de Saúde Pública, de autoria de Carvalho et al., são apresentados resultados de análise de artigos de amostra aleatória de números das duas revistas publicados entre os anos 1996 e 2003. Após a quantificação da tendência temporal do número de artigos publicados por fascículo (ascendente) e do número de referências (variável, mas com valores médios relativamente constantes e semelhantes aos valores referidos na literatura), os artigos foram classificados segundo subáreas temáticas: epidemiologia, ciências sociais em saúde, planejamento e políticas de saúde e outras subáreas. Para cada revista são apresentados os perfis (artigo, livro, tese, Internet, literatura cinzenta) das referências citadas, por subárea e tendência temporal. A subárea de ciências sociais apresenta, ao longo do tempo, citação mais importante e constante de livros, quando comparado com artigos, por referência às demais áreas, em particular a epidemiologia, resultado este que acompanha a literatura.

Algumas reflexões provocadas pelo artigo. A subárea epidemiologia é dominante nas duas revistas, em todo o período analisado, aparecendo em destacado segundo lugar "outras subáreas", com comportamento bastante semelhante ao da epidemiologia, apontando para a dificuldade na categorização por subáreas dos artigos da Saúde Coletiva e sugerindo que a metodologia adotada para o estudo (quantitativa ou qualitativa) é forte condicionante do comportamento nas citações, independente do tema. Ou seja, a forma de legitimar o conhecimento apresentado (é disto que se trata quando seleciono o que vou citar) está mais associada aos pressupostos metodológicos do que ao objeto de estudo. Adicionalmente, o número, tipo de citação e inserção das referências no texto dos artigos podem também ser considerados, em certa medida, enquanto parte de comportamentos orientados por modelos implícitos e explícitos, utilizados pelos autores, editores e revisores na definição do que caracterizaria o "bom" artigo científico, o melhor produto, na área em que o autor pretende se destacar 2,3.

No artigo SciELO Saúde Pública: O Desempenho dos Cadernos de Saúde Pública e da Revista de Saúde Pública, de autoria de Rita Barradas Barata, são apresentados, para as duas revistas, 
resultados da análise de dimensões que permitem estudar o acesso e utilização dos fascículos e artigos para leitura e citação em novos artigos. Um primeiro fator de destaque é o desenvolvimento pela Fundação de Amparo à Pesquisa do Estado de São Paulo (FAPESP) e do Centro Latino-Americano e do Caribe de Informação em Ciências da Saúde (BIREME), a partir de 1997, da biblioteca eletrônica on-line de revistas científicas SciELO, incluindo a SciELO Saúde Pública que, ao permitir o livre acesso às revistas pela Internet, impactou fortemente o seu padrão de acesso e utilização 4 .

Os artigos publicados nas duas revistas concentraram metade das suas citações em 49 periódicos, dos quais em torno da metade são da área de saúde coletiva e $80 \%$ estrangeiros, o que poderia indicar a existência de um padrão de citação relativamente estável, transdisciplinar e internacionalizado nesses artigos: atributos da produção científica da área, da forma de elaborar os artigos, da atuação dos editores e revisores?

Nas duas revistas há uma tendência temporal de aumento do número médio de citações recebidas por fascículos e artigos, com inflexão particularmente importante a partir de 2002: quais as explicações para este fato? Além da possível maior utilização para citação dos artigos publicados nas duas revistas (inclusive da autocitação) teria havido crescimento significativo a partir desse ano do número de artigos científicos publicados e indexados nas bases da BIREME? Concomitantemente, a vida média das citações recebidas nas duas revistas é relativamente curta, em torno de quatro anos, o que caracterizaria um "consumo" dos artigos para fins de citação relativamente volátil, comparativamente a outros periódicos (apesar de na base Institute for Scientific Information/Thomson Scientific interessarem para os cálculos de fator de impacto dos periódicos apenas os dois anos após a publicação do artigo). $\mathrm{Na}$ análise dos 50 artigos mais citados no período em cada uma das revistas apareceram diferenças interessantes na temática dos artigos (de difícil interpretação), desenho do estudo e técnica de análise: nos Cadernos de Saúde Pública foram mais importantes os ensaios teóricos e técnicas de análise argumentativas, e na Revista de Saúde Pública os inquéritos de prevalência e técnicas de análise quantitativas descritivas: oferta e/ou procura diferenciada, ou casualidade?

$\mathrm{O}$ artigo Entre Fetichismo e Sobrevivência: $O$ Artigo Científico É Uma Mercadoria Acadêmi$c a$ ?, de autoria de Castiel et al., discute de forma muito interessante questões atuais colocadas pela literatura para a compreensão ampliada e complexa do artigo científico, embasando a análise apresentada dos textos sobre as revistas. A visão do artigo científico como instrumento de difusão do conhecimento construído a partir de pesquisas, como uma etapa de conclusão deste processo necessária para a socialização do conhecimento e tornar possível a produção de novos conhecimentos e impacto sobre a realidade é parte da visão sobre ciência, tecnologia e sociedade construída a partir da Segunda Guerra Mundial. No entanto, ela não dá conta de outras perspectivas atualmente importantes, que podem ser sintetizadas na sua compreensão do artigo científico também como mercadoria em si, tanto concreta quanto simbólica, operando em diferentes contextos. A definição quanto a como, com quem, onde e quando publicar um artigo científico se insere em estratégias utilizadas pelos pesquisadores no gerenciamento de suas carreiras profissionais, interagindo com estratégias das editorias das revistas, universidades (em particular os cursos de pós-graduação), agências financiadoras e diferentes setores produtivos.

Uma das questões mais estudadas recentemente é o questionamento da forte associação entre a citação de um artigo e seu significado como indicador de impacto de uma pesquisa e de potencial para a criação de novos conhecimentos, conceito que fundamenta a sua utilização como base para o cálculo do valor do impacto dos periódicos e dos artigos. Estudos exploratórios na área da pesquisa em saúde analisaram, tomando como ponto zero um conjunto de artigos que apresentaram resultados de pesquisa considerados relevantes do ponto de vista científico, a distribuição da sua citação ao longo do tempo e por periódico, sua inserção nas diferentes partes dos artigos (introdução, metodologia e discussão) e sua importância para o embasamento dos resultados das novas pesquisas apresentadas. Nos resultados apresentados o número de vezes em que o artigo foi citado não se mostrou fortemente associado, nos artigos analisados, com sua importância na produção de novos conhecimentos (não foi analisada sua importância para a saúde da população, uma outra história) e apenas em um pequeno número de artigos o artigo citado foi considerado relevante 5 , observação esta que exige estudos adicionais, com novas metodologias e análises na perspectiva da sociologia das ciências e tecnologias.

O perfil das duas revistas que publicam o maior número de artigos da Saúde Coletiva no Brasil revela que elas são componentes importantes da consolidação da área, nas suas diferentes dimensões, enquanto parte da ciência brasileira, acompanhando, refletindo e em alguns aspectos ultrapassando o desempenho científico 
geral nacional e internacional, estando submetidas, por isto mesmo, às mesmas pressões, dificuldades, contradições e desafios que os peri- ódicos científicos enfrentam atualmente $6,7,8$ na realização dos seus objetivos, também em constante transformação.

\section{Referências}

1. Monteiro CA, Barata RB. Fórum de Editores Científicos em Saúde Pública [Editorial]. Rev Saúde Pública 2007; 41:1-2.

2. Szklo M. Quality of scientific journals. Rev Saúde Pública 2006; 40(N Esp):30-6.

3. Smith R. Peer review: a flawed process in the heart of science and journals. J R Soc Med 2006; 99:17882.

4. Castro RCF. Impacto da internet no fluxo da comunicação científica em saúde. Rev Saúde Pública 2006; 40(N Esp):57-63.
5. Hanney S, Frame I, Grant J, Buxton M, Young T, Lewison G. Using categorizations of citations when assessing the outcomes from health research. Scientometrics 2005; 65:357-79.

6. Barros AJD. Produção científica em saúde coletiva: perfil dos periódicos e avaliação pela Capes. Rev Saúde Pública 2006; 40(N Esp):43-9.

7. Glanzel W, Leta J, Thijs B. Science in Brazil. Part I: a macro-level comparative study. Scientometrics 2006; 67:67-86.

8. Leta J, Glanzel W, Thijs B. Science in Brazil. Part II: sectoral and institutional research profiles. Scientometrics 2006; 67:87-105.

Recebido em 27/Mai/2007 Aprovado em 29/Mai/2007 